\title{
De Novo Generation of Permanent Neovascularized Soft Tissue Appendages by Platelet-derived Growth Factor
}

\author{
Roger K. Khouri, * Sung-Pyo Hong, * E. Gene Deune, ${ }^{*}$ John E. Tarpley, ${ }^{\ddagger}$ Suk-Zu Song, ${ }^{5}$ \\ Cuneyt M. Serdar," and Glenn F. Pierce \\ *Department of Surgery, Division of Plastic Surgery, Washington University School of Medicine, St. Louis, Missouri 63110; \\ ${ }^{\ddagger}$ Department of Experimental Pathology; ${ }^{\S}$ Department of Pharmaceutics, and "Department of Therapeutic Product Development, Amgen, \\ Inc., Thousand Oaks, California 91320
}

\section{Abstract}

Treatment of wounds with pharmacologic doses of the BB homodimeric form of recombinant PDGF (rPDGF-BB) induces the recruitment, activation, and proliferation of mesenchymal cells, resulting in the deposition of provisional, and subsequently collagen-containing extracellular matrix. In preliminary experiments with an in vitro growth chamber model in the rat consisting of a silicone shell containing a dissected femoral vascular bundle, we found that rPDGFBB incorporated into a rapidly dissolving collagen type $I$ film induces the generation of a marked, but transient amount of de novo tissue around the femoral vascular bundle. In the present studies, the new tissue generated around the femoral vascular bundle was wrapped with a full thickness syngeneic skin graft to determine if functional support of the graft would lead to sustained maintenance of the underlying generated tissue and create an epithelialized soft tissue appendage. The tissue generated after a single application of rPDGF-BB was skin grafted on the 10th day, exteriorized $20 \mathrm{~d}$ later, and observed for an additional month. This led to the formation of soft tissue appendages which demonstrated marked neovascularization, fibroblast migration and proliferation, and increased glycosaminoglycan, fibronectin, and collagen fibril deposition, now leading to preservation of the newly generated tissue. In contrast, minimal new tissue was generated in control-treated vascular bundles or bundles treated with inactive PDGF-BB, and grafting with skin failed to sustain the underlying tissue. Thus, rPDGF-BB coupled with skin grafting induced the formation of functional large soft tissue appendages which are potentially useful clinically to fill tissue defects or to serve as a cell delivery system for transfected genes. ( $J$. Clin. Invest. 1994. 94:1757-1763.) Key words: angiogenesis - extracellular matrix • cell proliferation • fibroblasts • gene therapy

Address reprint requests to Dr. Roger Khouri, Department of Surgery, Division of Plastic Surgery, Washington University School of Medicine, St. Louis, MO 63110 and correspondence to Dr. Glenn Pierce, Department of Preclinical Sciences, Prizm Pharmaceuticals, 10655 Sorrento Valley Rd., San Diego, CA 92121.

Received for publication 3 March 1994 and in revised form 6 July 1994.

J. Clin. Invest.

(C) The American Society for Clinical Investigation, Inc.

0021-9738/94/11/1757/07 \$2.00

Volume 94, November 1994, 1757-1763

\section{Introduction}

Several growth factors have been identified which stimulate cell proliferation and extracellular matrix production. Plateletderived growth factor (PDGF) induces fibroblasts and smooth muscle cells to migrate and proliferate (1-4), and it is synthesized by, and stimulates mesenchymally derived cells and endothelial cells (5-8). In addition, PDGF is a potent chemotactic agent for monocytes $(9,10)$. PDGF is comprised of two polypeptide chains, $\mathrm{A}$ and $\mathrm{B}$, and has been identified in platelets and other cell types as AA or BB homodimers, or AB heterodimers $(7,8)$. PDGF-BB binds to PDGF- $\alpha$ and $-\beta$ receptors, while PDGF-AA and PDGF-AB preferentially bind PDGF- $\alpha$ receptors. The presence of specific receptors having distinct intracellular signaling pathways, coupled with synthesis of specific PDGF isoforms which function in an autocrine or paracrine fashion, result in unique biological effects on different cell types and tissues. For instance, the $\alpha$ receptor appears to mediate developmental programs, while the $\beta$ receptor may be required for chemotaxis and cell transformation $(11-14)$.

In vivo, recombinant (r)PDGF-BB ${ }^{1}$ has been shown to influence normal and deficient soft tissue repair in both animals $(10,15-17)$ and humans $(18,19)$. We have previously found that rPDGF-BB accelerates normal dermal repair, augmenting the acute inflammatory, provisional extracellular matrix deposition, and collagen deposition phases of wound healing $(20,21)$. Since rPDGF-AA was less effective (unpublished observation), and other growth factors such as basic fibroblast growth factor and transforming growth factor- $\beta 1$ (TGF- $\beta 1$ ) actually alter the normal repair process (21), we sought to determine if rPDGFBB could induce physiologic quantities of granulation tissue de novo. In an in vivo tissue growth chamber model consisting of an isolated arterio-venous vascular bundle within a silicone mold, rPDGF-BB bound to a collagen matrix was able to induce the formation of a sizable volume of tissue (22). However, without continuous exogenous supply of rPDGF-BB, the new tissue completely regressed within $30 \mathrm{~d}$. To render this generated tissue useful for clinical reconstructions, a means of stabilizing it and preventing cell death and matrix degradation is necessary. In this study, the growth response to rPDGF-BB is delineated, and the long term fate of this generated tissue is evaluated after it is given the functional role of supporting the perfusion and survival of a skin graft.

\section{Methods}

Preparation of rPDGF-BB. PDGF-B monomer 119 amino acids in length was purified to homogeneity and refolded and dimerized from

1. Abbreviation used in this paper: rPDGF-BB, recombinant homodimeric BB isoform of platelet-derived growth factor. 
E. coli by conventional methods, as described (21). All rPDGF-BB used was free of detectable endotoxin. Collagen disks were prepared as described (22) by allowing a $4 \%$ collagen solution (99:1, bovine type I: type III; Semex Co., Frazer, PA) prepared at $60^{\circ} \mathrm{C}$ in $20 \%$ ethanol, $1 \%$ acetic acid, with glycerol ( $20 \%$ of collagen dry weight) to dry on a Teflon ${ }^{\mathrm{TM}}$ surface at room temperature. The thickness of the resulting film was $0.3 \mathrm{~mm}$. Disks, $1.8 \mathrm{~cm}$ in diameter, were cut from the film. To prepare the rPDGF-BB containing disks, a $20 \mathrm{mg} / \mathrm{ml}$ solution of rPDGF-BB was added to the collagen solution before casting to yield $125 \mu \mathrm{g}$ of rPDGF-BB per disk. All rPDGF-BB batches were tested for retention of bioactivity after in vitro solubilization of the films in water, and assay on the NRK fibroblast line (10). Previous experiments have demonstrated that rPDGF-BB retains full biological activity when incorporated into a variety of solid phase delivery systems $(22,23$; Song, S.-Z., unpublished observation). Mutagenized PDGF-BB was generated by replacing the alanine at position 35 with histidine, and by deleting the arginine at position 28; this resulted in a dimerized molecule lacking any biological activity in the NRK fibroblast proliferation assay (10) (control, 704 counts per minute [cpm]; mutant $762 \mathrm{cpm}$; rPDGF-BB 50\% maximal activity, $3393 \mathrm{cpm}$ ).

Surgical procedures. Adult male Lewis rats (Harlan, Indianapolis, IN) weighing 200-225 g were used in all experiments, following institutional animal care and use guidelines. Under sterile conditions, the femoral artery and its venae comitans (vascular bundle) of one hind limb were dissected from the groin to below the knee and placed within a silicone chamber (Dow Corning Corp., Midland, MI) as described (22). Care was taken to trim the maximum amount of skeletal muscle away from each isolated vascular bundle. A small amount of muscle remained attached to all vascular bundles. Collagen film disks with or without (control) rPDGF-BB were sandwiched around the vascular bundle and the chamber was closed (see Fig. $1 A$ ). Chambers were then implanted into the peritoneal cavity. Chambers were exteriorized, removed, and the vascular bundles were assessed for cell proliferation and cellularity/new tissue volume at 7 or $10 \mathrm{~d}$, respectively. Additional groups of animals had their vascular bundles harvested from 5-30 d after surgery to assess the time course of new tissue generation. In subsequent experiments, after $10 \mathrm{~d}$ the isolated tissue was wrapped in a full thickness skin graft obtained from the back of syngeneic animals (see Fig. $1 B$ ). The composite was placed back subcutaneously into the groin surrounded by silicone sheets (Dow Corning) to separate it from the wound margins for $20 \mathrm{~d}$. One month after the first surgery the epithelialized soft tissue appendages were exteriorized and observed for an additional month. At that time, animals were sacrificed and the tissues were analyzed.

Tissue processing, histochemistry, and quantitation of matrix deposition. All tissues were fixed with $10 \%$ neutral buffered formalin. After fixation tissues were cross-sectioned and processed routinely for paraffin

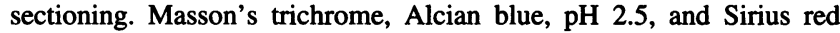
staining were performed as previously described (21). The determination of Alcian blue and Sirius red positive areas were performed by image analysis with a Quantimet 520 (Leica, Deerfield, IL) computerized image analysis system connected to a Nikon FXA microscope (Nikon, Torrance, CA). Images were captured using an Optronics Engineering VI-470 CCD video camera with low light level capability (Optronics Engineering, Goleta, CA). Alcian blue slides were imaged using a 621-nm narrow band pass filter (Oriel, Stratford, CT) while Sirius red was imaged through crossed polarizers (Nikon) (21).

Morphometric analyses. Cell counting was performed on histologic cross sections of the generated tissue using a digital image analysis system linked to morphometry software (Leco 2005; Leco Co., St. Joseph, MO). Each cross section was gray scale digitized ( 8 bit, 256 gray levels) at a calibration of $0.125 \mu \mathrm{m} /$ pixel. Fibroblasts were counted by thresholding their nuclei. Other nuclei (lymphocytes, polymorphonuclear leukocytes) and erythrocytes were excluded by including image shape and size criteria. The total cell count was then derived from volumetric reconstruction. BrdU positive cells were counted by thresholding step-sections cut at 1-mm intervals through the thickness of each block.
Immunohistochemical analyses. BrdU positive cells and cellular fibronectin were identified using standard immunohistochemical techniques (24). BrdU was detected by using a monoclonal antibody (Dako, Carpinteria, CA) at a dilution of 1:1,000. Before the primary antibody, sections were digested with $0.1 \%$ Nagarse protease type XXVII (Sigma Chemical Co., St. Louis, MO) for $1 \mathrm{~min}$ at room temperature, and single-stranded DNA segments were produced by treating sections with $2 \mathrm{~N} \mathrm{HCl}$ for $1 \mathrm{~h}$ at room temperature. Fibronectin staining was done using a monoclonal antibody to cellular fibronectin (Chemicon, International, Inc., Temecula, CA) at an optimal concentration of 1:50. This antibody does not recognize circulating fibronectin. An avidin-biotin, horseradish peroxidase detection system (BioTek Solutions, Santa Barbara, CA) was used for both procedures. 3,3'-Diaminobenzidine (Biotek Solutions) was used as the chromagen. All staining was performed on an automated immunostainer using capillary gap technology (Biotek Solutions). Negative controls consisted of either omission of the primary antibody, or substitution with an irrelevant isotype-specific antibody, and were run in all experiments. Specificity of the fibronectin antibody was assessed in wounded rabbit dermis, where granulation tissue was specifically stained, as established previously (21).

Microangiography. At sacrifice, the aorta was cannulated and flushed with $20 \mathrm{ml}$ of warm saline solution containing $100 \mathrm{IU}$ heparin. Through the same catheter, a mixture of lead oxide, saline solution and gelatin, as described by Rees and Taylor (25) was injected, avoiding high pressure. The rats were placed in the refrigerator at $-16^{\circ} \mathrm{C}$ for 1 $h$ to allow the gelatin to set. The appendages were then excised and a soft tissue radiograph was taken using a standard mammography apparatus.

Statistical analyses. Unpaired, two-tailed Student's $t$ tests were used to compare rPDGF-BB-treated animals to controls. Group sizes of 510 animals were used in all experiments.

\section{Results}

In adult rats, the femoral artery and its venae comitans were isolated and placed within a silicone chamber (Fig. $1 A$ ). $10 \mathrm{~d}$ later, in the presence of $250 \mu \mathrm{g}$ of rPDGF-BB, a large volume of tissue is generated compared with control, $\left(177 \pm 22.5 \mathrm{~mm}^{3}\right.$ [SEM] vs. $41 \pm 11 \mathrm{~mm}^{3}, P<0.0001$ ) (Fig. $2 A$ ). Cell counts also revealed a dramatic associated increase in cell numbers 7 and $10 \mathrm{~d}$ after implantation $\left(7 \mathrm{~d}, 14 \pm 3.5 \times 10^{6} \mathrm{vs} .7 \pm 2.510^{6}\right.$ $P<0.01$, and $10 \mathrm{~d} 17 \pm 3.3 \times 10^{6}$ vs. $\left.6.7 \pm 2 \times 10^{6}, P<0.001\right)$ (Fig. $2 B$ ). However, after $30 \mathrm{~d}$, the tissue was noted to undergo cell death, with reduction seen in both cell counts and tissue volume. Inactive rPDGF-BB failed to induce tissue growth, demonstrating the specific requirement for functional ligandreceptor binding to initiate signal transduction.

To quantitate cell proliferation, animals were given BrdU 7 $\mathrm{d}$ after implantation in the growth chamber. The BrdU positive cells were counted from the histologic sections using computerized image analysis and the total number of cells were reconstituted from volumetric analysis. rPDGF-BB treatment yielded $26,700 \pm 7,300$ (SEM) proliferating cells, whereas control wafers had 5,600 $\pm 1,100$ proliferating cells $(P<0.001)$. Furthermore, during this period of tissue generation, proliferation was concentrated in a band of fibroblasts migrating towards the periphery of the new tissue) (Fig. 3, A-D). The infiltration of new cells and deposition of matrix within and surrounding the vascular bundle is clearly observed in the rPDGF-BB-treated tissue (Fig. $3 A$ ) whereas the skeletal muscle remains undisturbed in the control (Fig. $3 \mathrm{~B}$ ). The rPDGF-BB-treated group showed markedly increased staining for cellular fibronectin throughout the generated tissue on day 7 compared with controls (Fig. 3, $E$ and $F$ ). This suggests that fibroblasts in the rPDGF$\mathrm{BB}$-treated group are capable of synthesizing fibronectin, a 
A

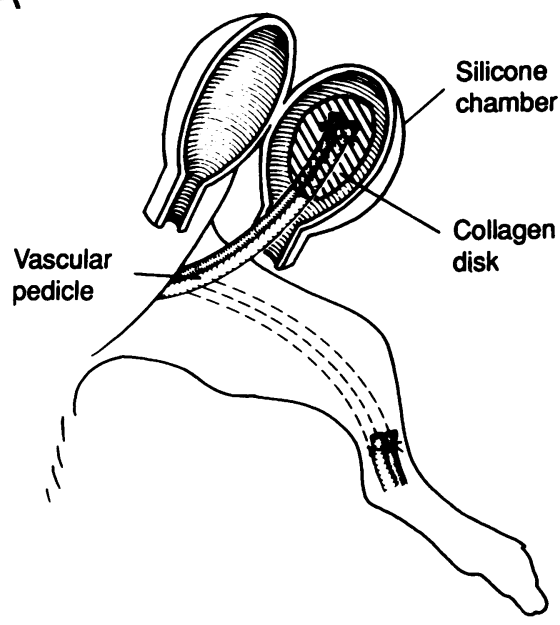

Days 0-10
B

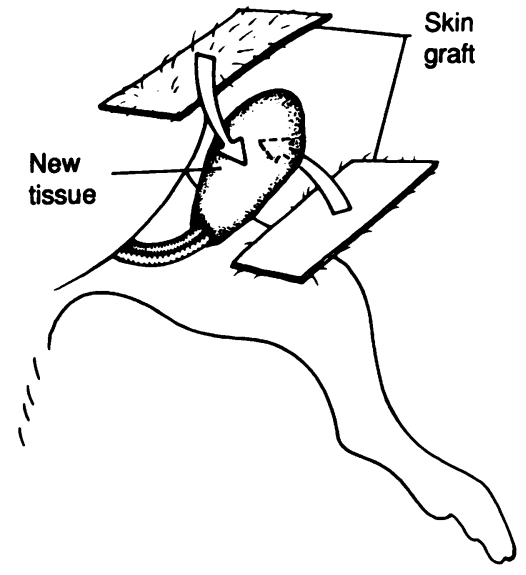

Days 10-30
Figure 1. (A) Surgical design of the in vivo tissue growth chamber. In adult rats, the femoral artery and its venae comitans were isolated. The vascular pedicle was sandwiched between two collagen wafers and the construct enclosed within the silicone chamber, with only the vascular pedicle emerging. In the experimental series, the collagen wafers were pretreated with $125 \mu \mathrm{g} /$ wafer of rPDGF-BB (22). Specimens are harvested at times ranging from 5 to $30 \mathrm{~d}$ after surgery. $(B)$ Using the experimental growth chamber in $A$, on the 10th postoperative day, the chamber is reopened and the tissue generated around the vascular bundle is wrapped with a syngeneic full thickness skin graft. The

new construct is then placed back in the groin and isolated from the surrounding tissues by thin silicone sheets for $20 \mathrm{~d}$. A total of $30 \mathrm{~d}$ after the first procedure, the groin wound is reopened and the epithelialized soft tissue appendage is exteriorized for an additional $30 \mathrm{~d}$.

critical provisional matrix component which permits cellular migration and provides the lattice for subsequent collagen deposition (26).

It was hypothesized that if the generated tissue was given a vital function, such as the role of providing vascular and structural support for the survival of ischemic tissue, then the tissue regression observed by $30 \mathrm{~d}$ might be prevented. Using the same model, the generated tissue was removed from the silicone mold at $10 \mathrm{~d}$ when the amount generated was maximal, and a full-thickness syngeneic skin graft was wrapped around the tissue (Fig. $1 B$ ). The composite was placed back subcutaneously in the groin surrounded by silicone sheets to separate it from the wound margins. After an additional $20 \mathrm{~d}$, the epithelialized soft tissue appendages were exteriorized and observed for an additional month.

At the time of exteriorization, the extracellular matrix depos- ited in the rPDGF-BB-treated appendages underwent normal maturation with the initial deposition of a provisional matrix. The area of new tissue, and areas of both GAG and collagen content were increased approximately twofold in the rPDGFBB-treated pedicles (Fig. 4, $A$ and $B$ ). If left alone, without supplemental growth factors and without skin grafting, the new tissue would have regressed completely by this time (22). However, after skin grafting, the tissue generated shows evidence of increased glycosaminoglycan deposition (Fig. 5, $A$ and $B$ ), and collagen maturation and remodeling, which persisted for the duration of the experiment (Fig. 5, $C$ and $D$ ). rPDGFBB-treated neotissue contains considerably greater numbers of activated fibroblasts and neovessels than controls (Fig. 5, $E$ and $F$ ).

After exteriorization for $1 \mathrm{mo}$, the volume of tissue generated by the rPDGF-BB-treated pedicle was found to be substan-
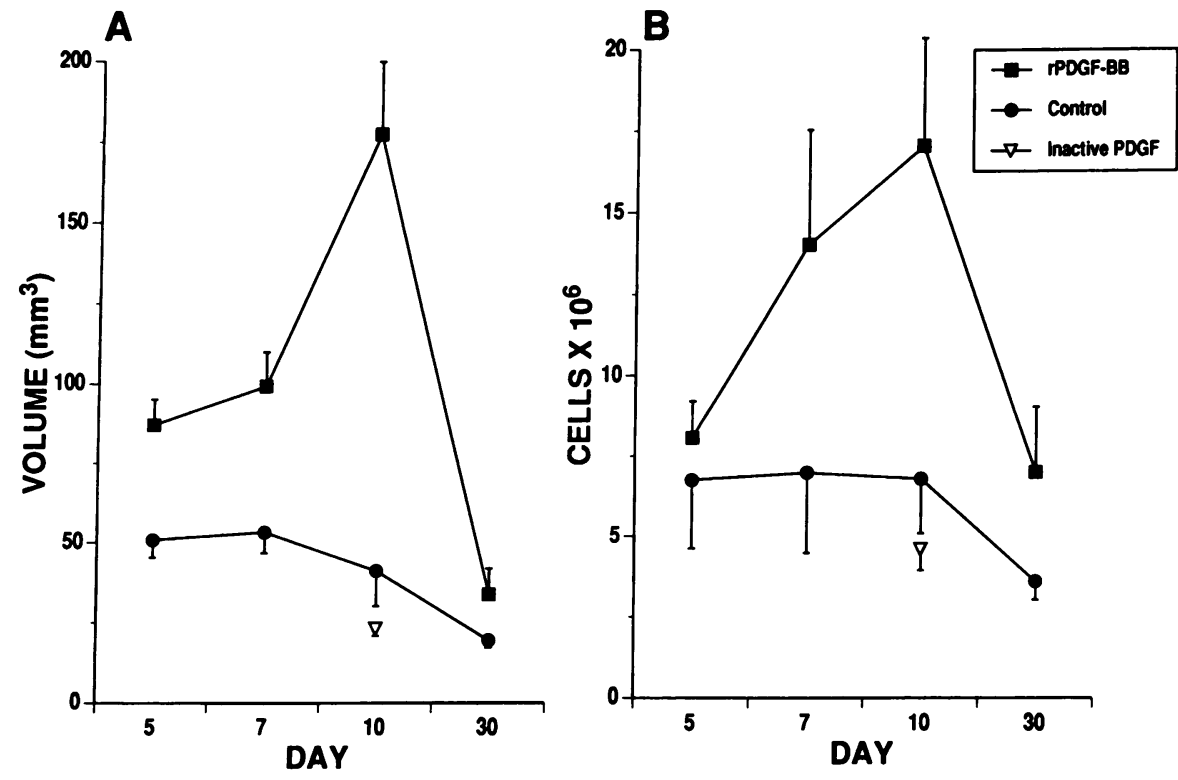

Figure 2. Histomorphometric evaluation of tissue generated within the silicone molds revealed a dramatic increase in $(A)$ tissue volume and $(B)$ cell number 7 and $10 \mathrm{~d}$ after implantation of rPDGF-BB-treated wafers in comparison with untreated control wafers and wafers pretreated with inactive rPDGFBB, a B chain homodimer having no mitogenic activity in vitro. 


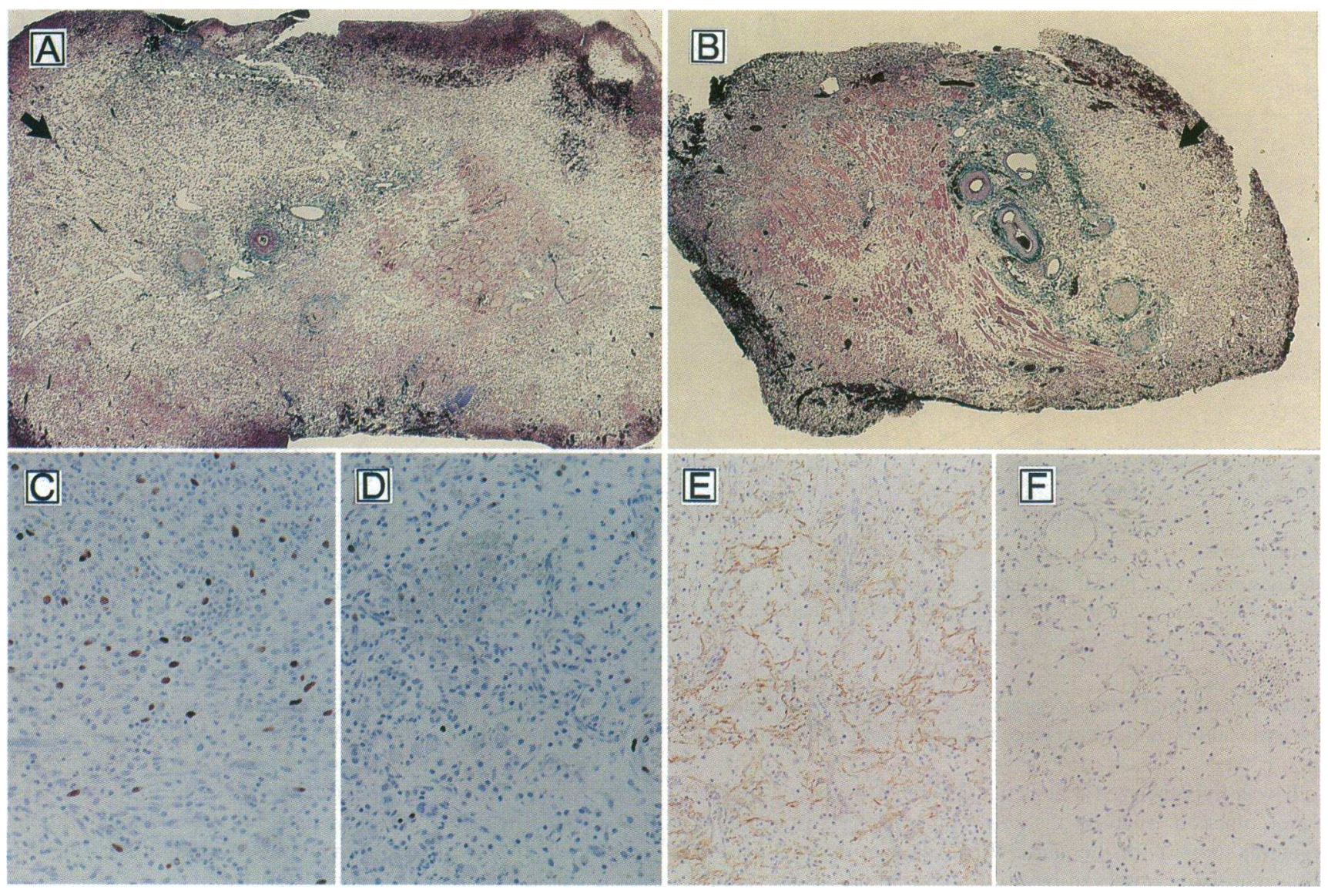

Figure 3. Development of the neotissue at $7 \mathrm{~d}$. Size of the new tissue generated in $(A)$ rPDGF-BB-treated and $(B)$ control silicone molds. MassonTrichrome stain $(\times 10)$. Arrow shows approximate area of proliferating fibroblasts shown in $C$ and $D$. The total number of proliferating cells was determined $7 \mathrm{~d}$ after surgical implantation in the growth chamber. $(C)$ rPDGF-BB-treated or $(D)$ control animals. Specimens were harvested one hour after BrdU administration and stained with anti-BrdU. Note the band of proliferating fibroblasts migrating toward the periphery. Fibronectin immunostaining was performed on $(E)$ rPDGF-BB-treated and $(F)$ control vascular bundles $(\times 47)$.
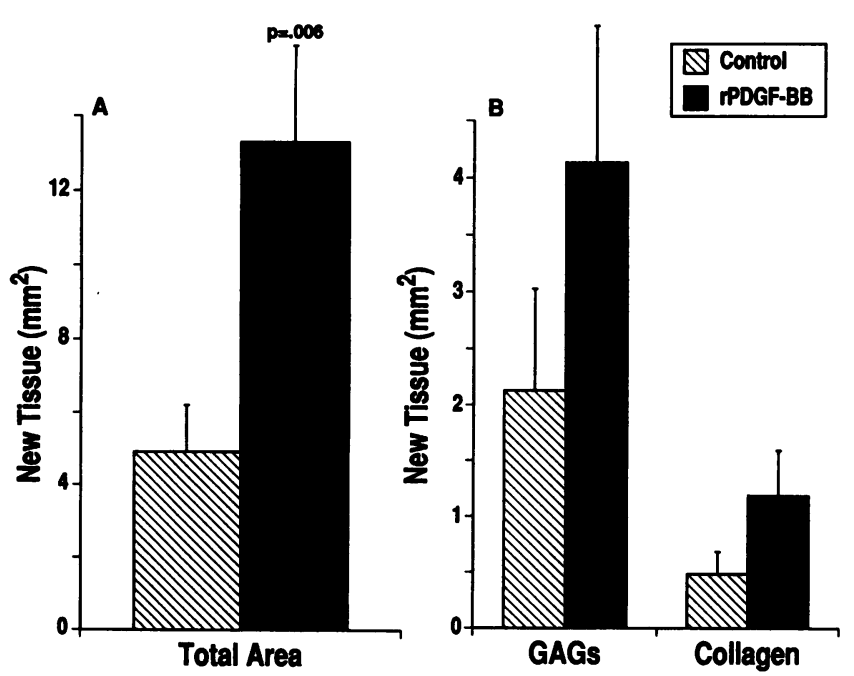

Figure 4. Generation of new tissue in skin grafted appendages at the time of exteriorization, $20 \mathrm{~d}$ after grafting. $(A)$ Total area of new tissue surrounding the vascular bundle. $(B)$ Total content of GAGs and collagen fibrils surrounding the vascular bundle ( $n=4$ per group). The overlying epidermis and dermis from the skin graft were excluded from the analyses. tially greater than in controls (Fig. 6, $A$ and $B$; and Fig. 7). An accompanying marked increase in microvascular development was also evident, as assessed by microangiography (Fig. 6, $C$ and $D$ ). Numerous functional neovessels arborized from the original vascular pedicle in the rPDGF-BB-treated animals in contrast to controls. A small number of animals were carried out to three months postinitial surgery: control pedicles had necrotic lesions and further regression, in contrast to rPDGFBB-treated pedicles (unpublished observation).

\section{Discussion}

rPDGF-BB has been reported to augment new granulation tissue in animals and in patients with chronic pressure ulcers (10, 15-19). However, the present results suggest rPDGF-BB can induce new tissue de novo, presumably via the recruitment of highly proliferative mesenchymal progenitor cells which are present within the vascular bundle, and associated endothelial and smooth muscle cells to provide a rich neovascular response.

These findings indicate that rapid generation of de novo mesenchymal tissue growth can be induced by rPDGF-BB. Unless continuously stimulated by local growth factors, however, that growth is transient. Even reoperation and a second application of rPDGF-BB at day 10 failed to sustain the new tissue through day 30 (22) to the same extent as when the rPDGF- 

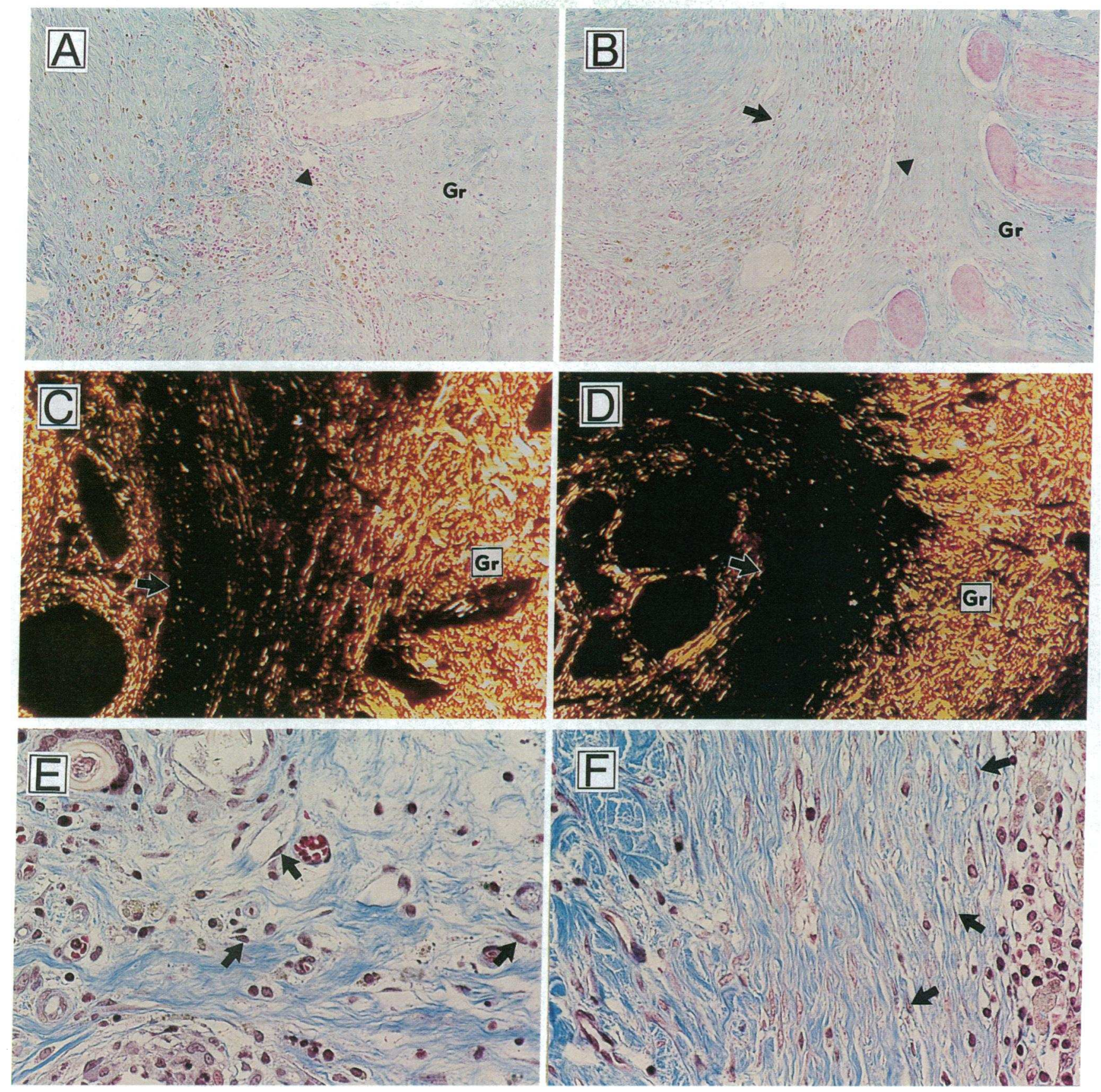

Figure 5. Histochemical analyses of skin grafted appendages at the time of exteriorization from $(A, C$, and $E)$ rPDGF-BB-treated or $(B, D$, and $F$ ) controls. ( $A$ and $B$ ) Total glycosaminoglycan content, Alcian blue stain, $\mathrm{pH} 2.5$. In $B$, arrow indicates edge of pedicle while in both photos the arrowheads indicate the skin graft-generated tissue interface; $G r$ indicates skin graft. Vascular pedicle is not visible in $A$ due to the larger volume of generated tissue $(\times 47)$. (C,D) Collagen fibrils viewed with polarized light, Sirius red stain. Arrows indicate edge of pedicle which is in the left side of each photo. Arrowheads indicate the skin graft-generated tissue interface; $G r$ indicates skin graft. More collagen fibrils can be seen in the rPDGF-BB-treated tissue $(\times 19)$. $(E$ and $F)$ Cellular content and collagen maturation, at the skin graft-generated tissue interface, Masson's trichrome stain. The rPDGF-BB-treated sample shows activated fibroblasts as compared to control (arrows). The collagen shows evidence of remodeling and fibril and bundle alignment suggestive of tissue integration in the rPDGF-BB-treated tissue. Additionally, note the greater angiogenic response in the rPDGF-BB-treated sample $(\times 187)$.

BB-treated tissue was skin grafted at day 10 (present study). In a calvarial defect model in rats, rPDGF-BB delivered once in a similar collagen vehicle also induced the transient accumulation of new soft tissue overlying the cranium (23), consistent with our earlier findings (22). By giving that generated tissue a functional role, such as becoming necessary for survival of a skin graft, the tissue is stabilized, and cell death can be reduced. The mechanisms which provide for stabilization of cell survival are not clear (27), but may be related to functional positive growth factor and cytokine feedback loops generated between the grafted epidermis and the underlying mesenchyme. For instance, keratinocytes synthesize growth factors such as trans- 

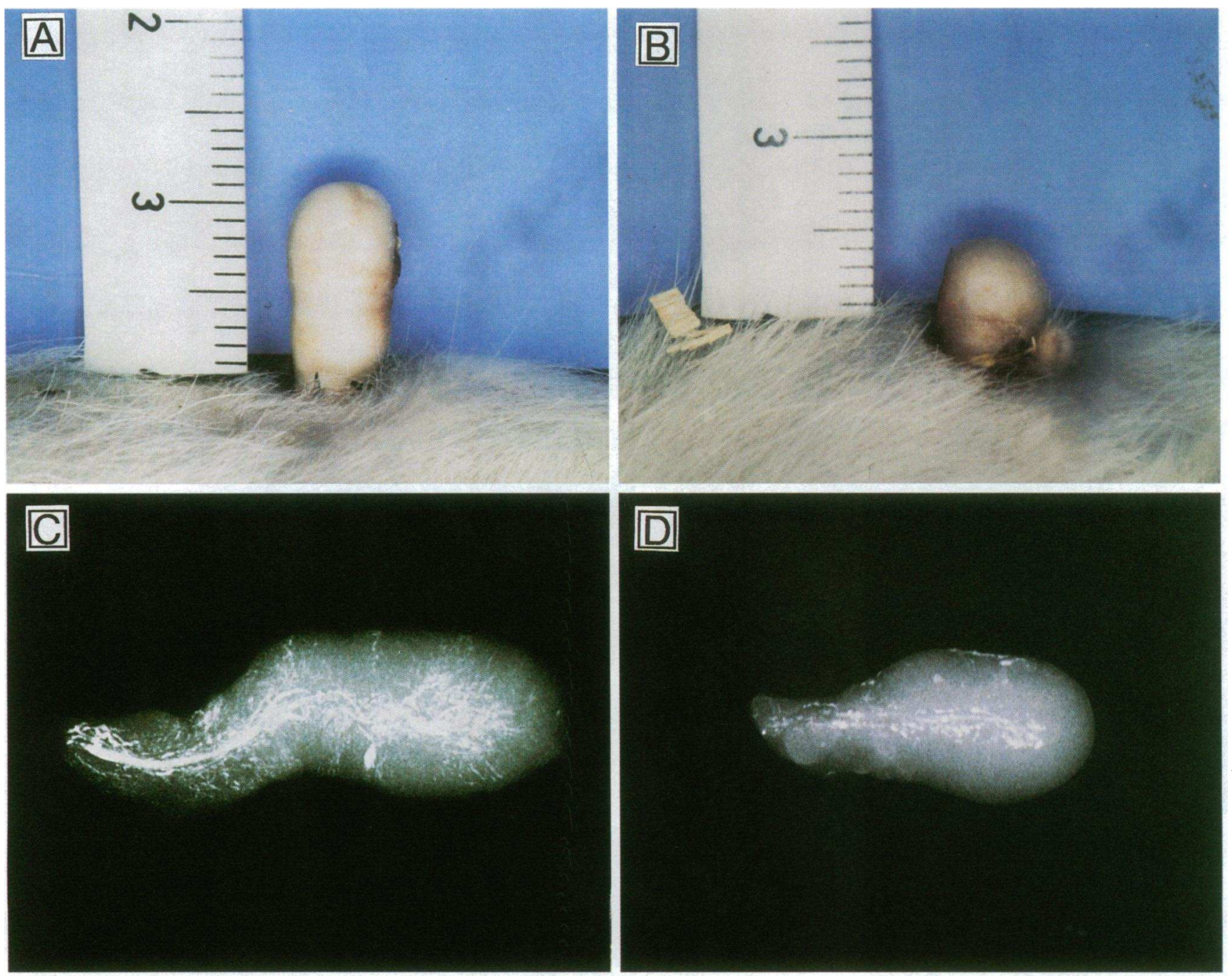

Figure 6. Tissue volume and blood perfusion in exteriorized appendages. Appendages were exteriorized $20 \mathrm{~d}$ after skin grafting, and were analyzed 1 mo later. Gross comparison between the appendages generated with $(A)$ rPDGF-BB and $(B)$ controls. Over the month they were exteriorized, the control appendages ulcerated and regressed while the growth factor generated ones remained stable. Angiography of tissue appendages one month following exteriorization revealed a rich network of blood vessels emerging from the original vascular bundle and arborizing towards the periphery to provide perfusion to the skin graft in $(C)$ the rPDGF-BB-treated group, whereas in $(D)$ the control group, only the original pedicle is visible with minimal vascularization of the graft. 10 animals were studied per group.

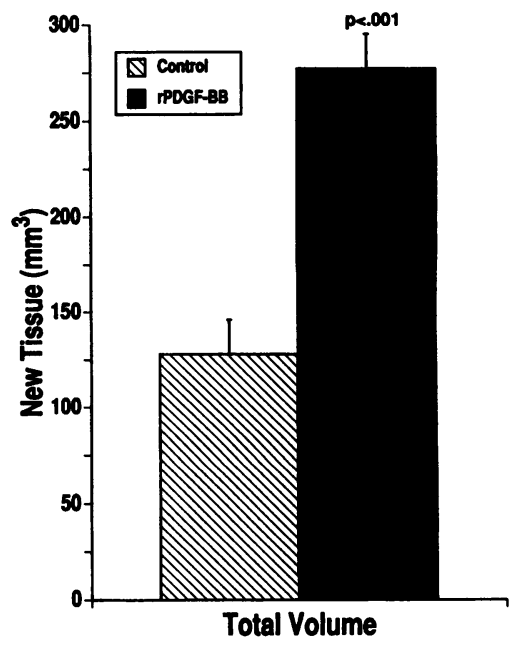

Figure 7. Quantitation of tissue volume in exteriorized appendages. After exteriorization for $1 \mathrm{mo}$, serial sections of pedicles from rPDGF-BB-treated $(n=8)$ and control $(n$ $=6$ ) animals were reconstructed to obtain a volume measurement. forming growth factor- $\alpha$, which can stimulate mesenchymal cells, such as fibroblasts and smooth muscle cells $(28,29)$. In turn, fibroblasts are a rich source of both mesenchymal growth factors (e.g., PDGF, heparin-binding epidermal growth factor $[30,31]$, TGF- $\beta$ ), and keratinocyte growth factors (e.g., keratinocyte growth factor, $(24,32,33)$ which can sustain the skin graft.

Although our analysis of the skin-grafted appendages was carried out for only 1 mo after exteriorization ( $50 \mathrm{~d}$ total duration ), the observed deposition of collagen fibrils upon the provisional matrix framework of glycosaminoglycans and fibronectin when appendages were exteriorized suggests this new tissue will persist. Initial treatment of the vascular bundle with rPDGF$\mathrm{BB}$ is required for growth and persistence of the skin grafted appendage. Longer term experiments will be required to more fully assess whether this appendage will more closely resemble mature granulation tissue (scar) or normal skin (regeneration).

Thus, sustained, functional soft tissue appendages can be generated by skin grafting of the massive de novo tissue growth 
that follows a single application of human rPDGF-BB. Since mature human and rat PDGF-BB are $88 \%$ homologous at the amino acid level, and human PDGF-BB is fully active on rodent cell lines and in rodent models, human PDGF-BB would be fully expected to produce results similar to those reported here in a human system. This ability to control the fate of soft tissue generated with rPDGF-BB may have useful clinical applications. In particular, this unique approach potentially could be used to fill large soft tissue defects in individuals with chronic dermal ulcers, or other large defects in situations where full or partial thickness skin grafts are not feasible. In addition, a longlasting self-sustaining tissue appendage may be useful as a gene therapy delivery vehicle after in situ transfection of fibroblasts, endothelial cells, or keratinocytes with a relevant vector-gene combination. Its fibroblast density, vascularity, and presence of keratinocytes would permit not only localized delivery of an exogenous gene, but would also provide an added measure of safety not presently available in gene therapy clinical trials, since the tissue appendage could be easily removed.

\section{Acknowledgments}

The authors thank W. Kenney and E. Hsu for providing the inactive PDGF; R. Koopman, A. Morawiecki, B. Morris, D. Duryea, and C. Burgh for excellent technical assistance; F. Martin for helpful discussion; J. Bennett for manuscript preparation; and J. Keysor and R. Pinal for illustrations.

This work was supported by a grant from Amgen, Inc.

\section{References}

1. Ross, R., J. Glomset, B. Kariya, and L. Harker. 1974. A platelet-dependent serum factor that stimulates the proliferation of arterial smooth muscle cells in vitro. Proc. Nat. Acad. Sci. USA. 71:1207-1210.

2. Kohler, N., and A. Lipton. 1974. Platelets as a source of fibroblast growthpromoting activity. Exp. Cell. Res. 87:297-301.

3. Grotendorst, G. R., H. E. J. Seppa, H. K. Kleinman, and G. R. Martin. 1981. Attachment of smooth muscle cells to collagen and their migration toward platelet-derived growth factor. Proc. Natl. Acad. Sci. USA. 78:3669-3672.

4. Senior, R. M., G. L. Griffin, J. S. Huang, D. A. Walz, and T. F. Deuel. 1983. Chemotactic activity of platelet alpha granule proteins for fibroblasts. $J$. Cell Biol. 96:382-385.

5. DiCorleto, P. E., and D. F. Bowen-Pope. 1983. Cultured endothelial cells produce a platelet-derived growth factor-like protein. Proc. Natl. Acad. Sci. USA. 80:1919-1923.

6. Beitz, J. G., I. S. Kim, P. Calabresi, and A. R. Frackelton Jr. 1991. Human microvascular endothelial cells express receptors for platelet-derived growth factor. Proc. Natl. Acad. Sci. USA. 88:2021-2025.

7. Pierce, G. F., T. A. Mustoe, B. W. Altrock, T. F. Deuel, and A. Thomason. 1991. Role of platelet-derived growth factor in wound healing. J. Cell. Biochem. 45:319-326.

8. Deuel, T. F., R. S. Kawahara, T. A. Mustoe, and G. F. Pierce. 1991. Growth factors and wound healing: Platelet-derived growth factor as a model cytokine. Annu. Rev. Med. 42:567-84.

9. Deuel, T. F., R. M. Senior, J. S. Huang, and G. L. Griffin. 1982. Chemotaxis of monocytes and neutrophils to platelet-derived growth factor. J. Clin. Invest. 69:1046-1049.

10. Pierce, G. F., T. A. Mustoe, R. M. Senior, A. Thomason, J. Reed, G. Griffin, and T. F. Deuel. 1988. In vivo incisional wound healing augmented by platelet-derived growth factor and recombinant c-sis gene homodimeric proteins. J. Exp. Med. 167:974-987.

11. Morrison-Graham, K., G. C. Schatteman, T. Bork, D. F. Bowen-Pope and J. A. Weston. 1992. A PDGF receptor mutation in the mouse (Patch) perturbs the development of a non-neuronal subset of neural crest-derived cells. Development (Camb.). 115:133-142.

12. Eriksson, A., A. Siegbahn, B. Westermark, C.-H. Heldin, and L. ClaessonWelsh. 1992. PDGF alpha- and beta-receptors activate unique and common signal transduction pathways. EMBO (Env. Mol. Biol. Organ.) J. 11:543-550.

13. Bejcek, B. E., R. M. Hoffman, D. Lipps, D.-Y. Li, C. A. Mitchell, P. W.
Majerus, and T. F. Deuel. 1992. The v-sis oncogene product but not plateletderived growth factor (PDGF) A homodimers activate PDGF alpha and beta receptors intracellularly and initiate cellular transformation. J. Biol. Chem. 267:3289-3293.

14. Heidaran, M. A., J. F. Beeler, J. C. Yu, T. Ishibashi, W. J. LaRochelle, J. H. Pierce, and S. A. Aaronson. 1993. Differences in substrate specificities of alpha and beta platelet-derived growth factor (PDGF) receptors: correlation with their ability to mediate PDGF transforming functions. J. Biol. Chem. 268:92879295.

15. Pierce, G. F., T. A. Mustoe, J. Lingelbach, V. R. Masakowski, G. Griffin, R. Senior, and T. F. Deuel. 1989. Platelet-derived growth factor and transforming growth factor- $\beta$ enhance tissue repair activities by unique mechanisms. J. Cell Biol. 109:429-440.

16. Mustoe, T. A., J. Purdy, P. Gramates, T. F. Deuel, A. Thomason, and G. F. Pierce. 1989. Reversal of impaired wound healing in irradiated rats by platelet-derived growth factor-BB: requirement of an active bone marrow. Am. J. Surg. 158:345-350.

17. Mustoe, T. A., G. F. Pierce, C. Morishima, and T. F. Deuel. 1991. Growth factor-induced acceleration of tissue repair through direct and inductive activities in a rabbit dermal ulcer model. J. Clin. Invest. 87:694-703.

18. Robson, M. C., L. G. Phillips, A. Thomason, L. E. Robson, and G. F. Pierce. 1992. Platelet-derived growth factor BB for the treatment of chronic pressure ulcers. Lancet. 339:23-25.

19. Mustoe, T. A., N. R. Cutler, R. M. Allman, P. S. Goode, T. F. Deuel J. A. Prause, M. Bear, C. M. Serdar, and G. F. Pierce. 1994. A Phase II study to evaluate recombinant PDGF-BB in the treatment of stage III/IV pressure ulcers. Arch. Surg. 129:213-219.

20. Pierce, G. F., J. Vande Berg, R. Rudolph, J. Tarpley, and T. A. Mustoe. 1991. Platelet derived growth factor-BB and transforming growth factor- $\beta 1$ differentially augment inflammatory and matrix assembly phases of wound healing and inhibit myofibroblast generation: ultrastructural and morphometric analyses. Am. J. Pathol. 138:629-646.

21. Pierce, G. F., J. Tarpley, D. Yanagihara, T. A. Mustoe, G. M. Fox, and A. Thomason. 1992. PDGF-BB, TGF- $\beta 1$, and basic FGF in dermal wound healing: neovessel and matrix formation and cessation of repair. Am. J. Pathol. 140:13751388.

22. Khouri, R. K., B. Koudsi, E. G. Deune, S. P. Hong, M. R. Ozbek, C. M. Serdar, S. Z. Song, and G. F. Pierce. 1993. Tissue generation with growth factors. Surgery. 114:374-379.

23. Marden L. J., R. S. P. Fan, G. F. Pierce, A. H. Reddi, and J. O. Hollinger. 1993. Platelet-derived growth factor inhibits bone regeneration induced by osteogenin, a bone morphogenetic protein, in rat craniotomy defects. J. Clin. Invest. 92:2841-2849.

24. Pierce, G. F., D. Yanagihara, K. Klopchin, D. M. Danilenko, E. Hsu W. C. Kenney, and C. F. Morris. 1994. Stimulation of all epithelial elements during skin regeneration by keratinocyte growth factor. J. Exp. Med. 179:831840.

25. Rees, M. J. W., and G. A. Taylor. 1986. A simplified lead oxide cadaver injection technique. Plast. Reconstr. Surg. 77:141-145.

26. Welch, M. P., G. F. Odland, and R. A. F. Clark. 1990. Temporal relationships of F-actin bundle formation, collagen and fibronectin matrix assembly, and fibronectin receptor expression to wound contraction. J. Cell Biol. 110:133-145.

27. Raff, M. S., B. A. Barres, J. F. Burne, H. S. Coles, Y. Ishizaki, and M. D. Jacobson. 1993. Programmed cell death and the control of cell survival: lessons from the nervous system. Science (Wash. DC). 262:695-700.

28. Elder, J. T., G. J. Fisher, P. B. Lindquist, G. L. Bennett, M. R. Pittlekow, R. J. Coffey, Jr., L. Ellingsworth, R. Derynck, and J. J. Voorhees. 1989. Overexpression of transforming growth factor alpha in psoriatic epidermis. Science (Wash. DC). 243:811-814.

29. R. J. Coffey, R. Derynck, J. N. Wilcox, T. S. Bringman, A. S. Goustein, H. L. Moses, and M. R. Pittelkow. 1987. Production and auto-induction of transforming growth factor alpha in human keratinocytes. Nature (Lond.). 328:817.

30. Abraham, J. A., D. Damm, A. Bajardi, J. Miller, M. Klagsburn, and A. B. Ezekowitz. 1993. Heparin-binding EGF-like growth factor: characterization of rat and mouse cDNA clones, protein domain conservation across species, and transcript expression in tissues. Biochem. Biophys. Res. Commun. 190:125-133.

31. Marikovsky, M., K. Breuing, P. Y. Liu, E. Eriksson, S. Higashiyama, P. Farber, J. Abraham, and M. Klagsburn. 1993. Appearance of heparin-binding EGF-like growth factor in wound fluid as a response to injury. Proc. Natl. Acad. Sci. USA. 90:3889-3893.

32. Rubin, J. S., H. Osada, P. W. Finch, W. G. Taylor, S. Rudikoff, and S. A. Aaronson. 1989. Purification and characterization of a newly identified growth factor specific for epithelial cells. Proc. Natl. Acad. Sci. USA. 86:802-806.

33. Werner, S., K. G. Peters, M. T. Longaker, F. Fuller-Pace, M. J. Banda, and L. T. Williams. 1992. Large induction of keratinocyte growth factor expression in the dermis during wound healing. Proc. Natl. Acad. Sci. USA. 89:6896-6900. 